\title{
Aortic valve reconstruction surgery. Operative results from a Peruvian Cohort Running tittle: AVrec Surgery
}

\author{
Josías C. Ríos-Ortega ${ }^{1}$, Necemio Aranda-Pretell ${ }^{1}$, Luisa Talledo-Paredes ${ }^{1}$, Manuel \\ Davila-Durand $^{1}$, Andres Reyes-Torres ${ }^{1}$, Yemmy Pérez-Valverde ${ }^{1}$, and Julio Morón-Castro ${ }^{1}$ \\ ${ }^{1}$ Seguro Social del Peru
}

January 20, 2022

\begin{abstract}
Background Aortic valve replacement is the gold standard treatment for severe symptomatic aortic valve disease. Recently, aortic valve reconstruction surgery (Ozaki procedure) emerges as a surgical alternative with good results in the medium term. Methods We retrospectively analyzed 38 patients who underwent aortic valve reconstruction surgery between January 2018 and June 2020 in a national reference center in Lima, Peru. The median age was 62 years, interquartile range 25 . The main indication for surgery was aortic valve stenosis $(63.1 \%)$, in most cases due to bicuspid valve (19 patients, $50 \%)$. Twenty-two (58\%) patients had another pathology with surgical indication associated to AV disease, $8(21 \%)$ had dilatation of the ascending aorta with indication for replacement. Results One in-hospital death occurred $(1 / 38,2.6 \%)$ due to perioperative myocardial infarction. There was a significant reduction in the medians of the peak $(66 \mathrm{mmHg}, \mathrm{CI} 95 \%=52.5-81.3$ vs $15 \mathrm{mmHg}, \mathrm{CI} 95 \%=12.1-17.5, \mathrm{p}<0.0001)$ and mean $(41 \mathrm{mmHg}$ CI95\%=31.8-50.1 vs $8 \mathrm{mmHg}, \mathrm{CI} 95 \%=6.0-9.6, \mathrm{p}<0.0001)$ aortic valve gradients when we compared baseline characteristics with first 30-days results. In an average of $19( \pm 8.9)$ months of follow-up, survival, reoperation-free survival for valve dysfunction, and survival free of AV insufficiency > II were $94.6 \%, 94.6 \%$ y $91.7 \%$, respectively. Significant reduction in the medians of the peak $(66 \mathrm{mmHg}, \mathrm{CI} 95 \%=52.5-81.3 \mathrm{vs} 14 \mathrm{mmHg}, \mathrm{CI} 95 \%=10.9-17.6, \mathrm{p}<0.0001)$ and mean $(41 \mathrm{mmHg}$ CI95\%=31.850.1 vs $7 \mathrm{mmHg}$, CI95\%=5.2-9.1, p<0.0001) aortic valve gradients were maintained. Conclusions Mid-term outcome follow-up of aortic valve reconstruction surgery showed optimal results in term of mortality, reoperation free survival and hemodynamic characteristics of the neo-aortic valve.
\end{abstract}

\section{Aortic valve reconstruction surgery. Operative results from a Peruvian Cohort}

\section{Running tittle: AVrec Surgery}

Josías C. Ríos-Ortega MD ${ }^{1,2}$, Necemio Aranda-Pretell MD¹, Luisa Talledo-Paredes $\mathrm{MD}^{3}$, Manuel DavilaDurand $\mathrm{MD}^{1}$, Andres Reyes-Torres $\mathrm{MD}^{1}$, Yemmy Pérez-Valverde $\mathrm{MD}^{1}$, Julio Morón Castro $\mathrm{MD}^{1}$

1. Cardiovascular Surgery Department, National Cardiovascular Institute, EsSalud, Lima, Peru.

2. Master's Program in Health Teaching and Research. Nacional University of San Marcos. Lima, Perú

3. Cardiology Department, National Cardiovascular Institute, EsSalud, Lima, Peru.

\section{Corresponding author:}

Name: Josías Caleb Ríos Ortega Postal Address: Jirón Coronel Zegarra 417. Jesús María. Lima. Perú Telephones numbers: +511 985794462, +511 4111560 Email: josias.rios@unmsm.edu.pe

\section{CONFLICT OF INTEREST STATEMENT}

Conflict of interest: none declared

FUNDING STATEMENTS 
This work was supported by self-financing

\section{DATA AVAILABILITY STATEMENT}

Authors declare the availability of data.

\section{AUTHORS CONTRIBUTIONS}

Josías C. Ríos-Ortega (Concept/design, Data analysis/interpretation, Drafting article), Necemio ArandaPretell MD(Concept/design, Data analysis/interpretation, Drafting article), Luisa Talledo-Paredes MD ( Data analysis/interpretation, Drafting article), Manuel Davila-Durand MD (Concept/design), Andres ReyesTorres MD (Critical revision of article, Approval of article), Yemmy Pérez-Valverde (Critical revision of article, Approval of article), Julio Morón Castro MD(Critical revision of article, Approval of article).

\section{ABSTRACT}

\section{Background}

Aortic valve replacement is the gold standard treatment for severe symptomatic aortic valve disease. Recently, aortic valve reconstruction surgery (Ozaki procedure) emerges as a surgical alternative with good results in the medium term.

\section{Methods}

We retrospectively analyzed 38 patients who underwent aortic valve reconstruction surgery between January 2018 and June 2020 in a national reference center in Lima, Peru. The median age was 62 years, interquartile range 25 . The main indication for surgery was aortic valve stenosis $(63.1 \%)$, in most cases due to bicuspid valve (19 patients, 50\%). Twenty-two (58\%) patients had another pathology with surgical indication associated to AV disease, $8(21 \%)$ had dilatation of the ascending aorta with indication for replacement.

\section{Results}

One in-hospital death occurred $(1 / 38,2.6 \%)$ due to perioperative myocardial infarction. There was a significant reduction in the medians of the peak $(66 \mathrm{mmHg}$, CI95\% $=52.5-81.3 \mathrm{vs} 15 \mathrm{mmHg}$, CI95\% $=12.1-17.5$, $\mathrm{p}<0.0001)$ and mean $(41 \mathrm{mmHg}$ CI95\% $=31.8-50.1 \mathrm{vs} 8 \mathrm{mmHg}$, CI95\% $=6.0-9.6, \mathrm{p}<0.0001)$ aortic valve gradients when we compared baseline characteristics with first 30-days results. In an average of $19( \pm 8.9)$ months of follow-up, survival, reoperation-free survival for valve dysfunction, and survival free of AV insufficiency> II were $94.6 \%, 94.6 \%$ y $91.7 \%$, respectively. Significant reduction in the medians of the peak $(66 \mathrm{mmHg}$, CI95\% $=52.5-81.3$ vs $14 \mathrm{mmHg}$, CI95\% $=10.9-17.6, \mathrm{p}<0.0001)$ and mean $(41 \mathrm{mmHg}$ CI95\% $=31.8-50.1$ vs $7 \mathrm{~mm}-$ $\mathrm{Hg}, \mathrm{CI} 95 \%=5.2-9.1, \mathrm{p}<0.0001)$ aortic valve gradients were maintained.

\section{Conclusions}

Mid-term outcome follow-up of aortic valve reconstruction surgery showed optimal results in term of mortality, reoperation free survival and hemodynamic characteristics of the neo-aortic valve.

\section{Key Words: Aortic valve reconstruction surgery, Ozaki procedure, Aortic valve surgery INTRODUCTION}

Aortic valve $(\mathrm{AV})$ stenosis is the most common valve heart disease and it is an important public health problem. ${ }^{1,2}$ Prosthetics AV replacement is the gold standard surgical procedure for treatment AV disease, however this procedure has important complications such as mismatch, anticoagulation complications (mechanical prosthesis), degeneration (biological prosthesis), among others. ${ }^{3-5}$

$\mathrm{AV}$ repair is an alternative to AV replacement, nevertheless this procedure requires more surgical expertise and is almost restricted to aortic insufficiency. ${ }^{6-8}$

AV reconstruction (AVRec) surgery is a novel surgical procedure for treatment AV disease, it is consisting of removing the AV and replacing it with a neo-valve constructed with autologous pericardium treated with 
glutaraldehyde. This procedure was described many years ago, however Ozaki et al. have standardized this technique. The results of survival and reoperation-free survival are excellent in medium-term follow-up, with the fundamental advantage of avoiding the use of anticoagulant. ${ }^{9-11}$

Currently, there is a standardized system of templates to perform this procedure, however due to administrative and financial problems it is difficult to acquire this in our center. That is why we designed our own templates system. With this system, we have not only performed AVRec surgeries, but also pulmonary valves. ${ }^{12,13}$

We present the surgical evolution of our first cases of AVRec surgeries performed.

\section{PATIENTS AND METHODS}

\section{Study population}

We conducted a retrospective investigation from January 2018 to June 2020 in patients undergoing AVRec surgery, performed by the same surgical team, in a national reference center in Lima, Peru. We selected patients who were susceptible to AV replacement with a biological prosthesis or those who rejected a mechanical prosthesis.

Operative technique

First of all, we designed and constructed our own templates system and then tested it in experimental surgeries on pig hearts.

After a median sternotomy, the preparation of the pericardium is started by cleaning it of fat and other redundant tissues on its external surface. A portion of the patient's pericardium was harvested and removed. The excised pericardium was then treated with $0.6 \%$ glutaraldehyde solution with an $8.4 \%$ sodium bicarbonate solution for 10 minutes. The treated pericardium was rinsed 3 times using physiologic saline solution for 6 minutes. Then, to perform AVRec surgery, we followed the technique described by Ozaki et al in their reports (Figure 1). ${ }^{8,14}$

All surgeries were performed during cardioplegic arrest on cardiopulmonary bypass. All patients underwent intraoperative transesophageal echocardiography in addition to standard monitoring for cardiac surgery.

According to the American Society of Echocardiography Recommendations, an advanced trained imaging cardiologist assessed transthoracic and transesophageal echocardiography.

\section{Evaluation stages}

We define three time periods: a) Baseline, b) Perioperative period: first 30 postoperative days and c) Extended follow-up: 19 ( \pm 8.9$)$ months.

\section{Outcomes}

The primary clinical outcomes were determined mortality and other complications as well as the hemodynamic characteristics of the neo-AV (gradient, degree of insufficiency) in the perioperative period and follow up.

\section{Statistical analysis}

\section{Descriptive analysis}

We performed statistical analysis using Stata v17.0 (Stata Corp., College Station, Texas, USA). We explore the distribution of variables using analytical and graphical methods and report numerical data. Numerical variables are expressed as mean and standard deviation or as median and interquartile range (IQR), while categorical variables are expressed in absolute and relative frequencies. For mortality and complications, we estimate the cumulative incidence in the perioperative period and follow up.

Comparative analysis 
We executed the bivariate comparative analysis considering two post hoc direct exploratory comparisons (binary): perioperative vs baseline ( $\mathrm{t} 1$ vs $\mathrm{t} 0$ ), extended follow-up vs baseline ( $\mathrm{t} 2 \mathrm{vs} \mathrm{t} 0$ ). We tested the differences with the Wilcoxon signed rank test for dependent numerical measures and with McNemar's exact test for dependent categorical measures. We did not observe normality of the numerical data, so we opted for these non-parametric methods.

Ethics

The Institutional Research and Ethics committee approved the protocol of this study (Certificate of Approval 06/2020-CEI March 10, 2020). The indication for surgery was approved by a meeting of all surgeons' staff and authorized by the patients with written informed consent.

\section{RESULTS}

\section{Baseline characteristics}

Table 1 summarizes the baseline characteristics of our patients. From January 2018 to June 2020 we operated 40 patients. Two who were directly converted to prosthetic valve replacement in the operating room due to moderate-severe AV insufficiency were excluded. In 2020 and 2021 our AVRec surgery program was stopped due to the covid-19 pandemic.

For the analysis we included 38 patients, the median age was 62 years (IQR 25), and the proportion according to sex was $50 / 50$. Twenty patients $(52,7 \%)$ were overweight or obese before surgery. We did not include patients in cardiogenic shock or functional class IV.

The main indication for surgery was AV stenosis (63.1\%) in most cases due to bicuspid valve (19 patients, $50 \%$ ). Something to highlight is that in two patients we performed this procedure in redo-surgeries (prosthesis dysfunction, one with a biological and the other with mechanic prosthesis). It was possible to carefully remove the autologous pericardium in these patients.

The median size of the AV annulus was 23 (IQR 5), however we operated 13 patients (34.2\%) with small AV annulus $(<21 \mathrm{~mm})$. The medians of the peak and mean AV gradient were $73 \mathrm{mmHg}$ (IQR 78) and $46 \mathrm{mmHg}$ (IQR 48), respectively. When we only include patients with AV stenosis gradients were $89 \mathrm{mmHg}$ (IQR 25) and $55 \mathrm{mmHg}$ (IQR 17), respectively.

Twenty-two (58\%) patients had another associated pathology with surgical indication in addition to AV disease, $8(21 \%)$ of them had dilatation of the ascending aorta with indication for replacement. $21 \%$ (8 patients) used oral anticoagulants (OAC) as a treatment for chronic atrial fibrillation (AF).

Surgical procedures characteristics

We performed 16(42\%) AVRec surgery as single procedure and 22(58\%) with another associated procedure (Table 2A). In 6 patients we performed mitral valve (MV) repair surgery and in two mechanical MV replacement (the first intention was to repair the MV with the aim of avoiding OAC therapy). Six patients (16\%) had coronary artery disease with indication for CABG, however, 2 more underwent CABG due to suspected intraoperative coronary embolism (total CABG, $21 \%$ ). In eight patients (21\%) we performed ascending aortic surgeries, seven underwent ascending aorta replacements and one underwent AV re-implantation surgery (David procedure + AVRec surgery).

The median of Cardiopulmonary bypass (CPB) time was 147 minutes (IQR 46), the median of aortic cross clamp time was 120 (IQR 45), when we include AVRec surgery as a single procedure these times were 136 minutes (IQR 49) and 104 minutes (IQR 37), respectively.

Perioperative evolution (early outcomes)

Mortality

One patient died $(2.6 \%)$ in the first thirty postoperative days due to suspected intraoperative coronary embolism, in this case we performed CABG surgery (graft of the saphenous vein to anterior descending and 
marginal arteries) but died due to circulatory shock.

\section{Other complications}

Two patients were re-operated due to excessive bleeding (5.3\%). One patient underwent tracheostomy and prolonged ventilation due to in-hospital pneumonia. There were no stroke events (Table 2B)

Hemodynamic of the neo-aortic valve

There was a significant reduction in the medians of the peak $(66 \mathrm{mmHg}, \mathrm{CI} 95 \%=52.5-81.3 \mathrm{vs} 15 \mathrm{mmHg}$, CI95\% $=12.1-17.5, \mathrm{p}<0.0001)$ and mean $(41 \mathrm{mmHg}$ CI95\% $=31.8-50.1 \mathrm{vs} 8 \mathrm{mmHg}$, CI95\%=6.0-9.6, $\mathrm{p}<0.0001)$ AV gradients (Table 3, Figure 2A). In this period, no patient had a mean gradient greater than $20 \mathrm{mmHg}$.

The sum of patients without AV insufficiency or with insufficiency grade I was 37/38 (97\%), only one patient (3\%) had AV regurgitation grade II, no cases with insufficiency grade III or IV were observed, when these data were compared with the preoperative period, the difference was significant (table 3 ).

Follow up evolution

The mean follow-up was 19 ( \pm 8.9$)$ months.

Mortality

Mortality and other complications are expressed in Table 3. We have other additional mortality in the follow-up, $2 / 38$ patients, $5.2 \%$.

Hemodynamic of the neo-aortic valve

Significant reduction in the medians of the peak $(66 \mathrm{mmHg}$, CI95\% $=52.5-81.3 \mathrm{vs} 14 \mathrm{mmHg}$, CI95\% $=10.9-17.6$, $\mathrm{p}<0.0001)$ and mean $(41 \mathrm{mmHg}$ CI95\% $=31.8-50.1 \mathrm{vs} 7 \mathrm{mmHg}$, CI95\% $=5.2-9.1, \mathrm{p}<0.0001)$ AV gradients when we compared baseline characteristics with follow-up were maintained (Table 3, Figure 3). Only one patient had a AV mean gradient $>20 \mathrm{mmHg}$ (peak AV gradient $=45 \mathrm{mmHg}$, mean AV gradient $=26 \mathrm{mmHg}$ ), in this case the aortic annulus was less than $21 \mathrm{~mm}$ in diameter.

Freedom from reoperation and aortic insufficiency [?]II:

No patient has been re-operated for valve dysfunction. Only three (9\% of alive patients) have insufficiency> II $(\mathrm{II}=2, \mathrm{III}=1)$. The cause of grade III insufficiency is due to the fact that the patient has developed a dilation of the aortic root (currently $40 \mathrm{~mm}$ ) that he did not have at the time of surgery $(33 \mathrm{~mm})$, however this patient is in functional class I(NYHA).

Survival, reoperation-free survival for valve dysfunction, and survival free of AV insufficiency > II were 94.6\%, $94.6 \%$ y $91.7 \%$, respectively (Figure 2B, C).

\section{Other complications}

Two patients $(5.3 \%)$ required permanent pacemaker for atrioventricular block and no patient developed stroke. 10 (26\%) use OAC, 8 due to chronic AF and 2 due to having a mechanical mitral prosthesis.

Most of our patients are in NYHA functional class I $(32,84 \%)$.

\section{DISCUSION}

Symptomatic severe aortic stenosis is associated with high mortality rates, $\sim 50 \%$ at 1 year, and the prevalence will likely increase as the population ages. In this pathology, interventional procedures (surgery is still the gold standard, especially in younger patients) have been shown to drastically reduce mortality and improve quality of life. ${ }^{15,16}$ Nevertheless, in many cases when we replace the diseased AV with a prosthesis we are changing one problem for another. Many complications have been described in heart valve prosthesis, but of particular interest to us are the complications derived from poor OAC therapy control (mechanical prosthesis) and those due to the rapid degeneration of biological prosthesis. ${ }^{2-4,17}$ Most of the patients in the Peruvian public health system are poor and do not have timely access to health services, which is why 
it is difficult to provide adequate OAC therapy in these patients, many of whom are from the interior of the country and they come to the capital just for the surgery. Early degeneration of biological prosthesis generates more public spending (mainly because trans-catheter therapy is now preferred) and a higher risk of mortality due to reoperation. AVRec surgery offers many advantages, mainly avoid OAC therapy and promises to be a technique with excellent long-term results, so it is a relatively economical technique compared to AV replacement, we believe it is an ideal choice for developing countries. This idea is supported by other authors. ${ }^{18,19}$

\section{Mortality and complications}

The 30-days mortality in our study cohort was $1 / 38$ patients $(2.6 \%)$, however in the follow-up we had other death due to mediastinitis (in the second month after surgery). Mean follow-up was 19(+-8.9) months and survival rate was $94.7 \%(36 / 38)$ at this time. The largest series of patients published by Ozaki et al. reports a hospital mortality of $16 / 850(\sim 1.9 \%)$ patients and a survival of $85 \%$ in a mean follow-up of $53.7(+-28.2)$ months. ${ }^{20}$ Krane et al. in a cohort of 103 patients reports a hospital mortality of $0.97 \%$ (1/103 patients), the overall survival was $98.1 \%$ with a mean follow up time of 426+-270 days (range: 9-889 days). Iida et al. reports a hospital mortality of $2 / 144(1.4 \%)$ and an overall survival rates of 89.5 and $77.2 \%$ at 12 and 60 months, respectively. Oliver et al. reports a hospital mortality of $1 / 30$ patients $(3.33 \%)$ which was maintained in a 3-month follow-up. Recently Ngo et al. in a series of 67 patients in Vietnam, reports a 1.7\% hospital mortality and a survival of 65/67(97\%) patients at one year of follow-up. ${ }^{21-23}$

The medium-term survival rate in our series is acceptable and comparable with other published cohorts. We had two cases of mortality, the first due to intraoperative coronary embolism in a 68-year-old patient with severely calcified bicuspid AV, who died of circulatory complications despite performing CABG. The other case of mortality occurred in a 75-year-old woman with morbid obesity $(\mathrm{BMI}=40)$ and diabetes mellitus who presented severe symptomatic aortic stenosis. Initially, we had rejected this case as a candidate for AVRec surgery, however, after discussing it in the heart team, we were decided to submit the patient to surgery because she had a $19 \mathrm{~mm}$ aortic annulus, and the probability of mismatch for AV replacement was high. Finally, this patient died to complications due to mediastinitis in the second month after surgery.

In 26 patients under 65 years of age we did not have in-hospital mortality, nor did we have it in the follow-up, $100 \%$ of the patients remain alive. These excellent results have also been seen in other series of the same age group. ${ }^{24,25}$

\section{Hemodynamic performance}

As mentioned above, we observed a significant reduction in the peak and mean gradients of the aortic valve both in the immediate postoperative period and in the follow-up (Figure2A, Table 3). In the follow up, the medians of the peak and mean gradients were $14 \mathrm{mmHg},(\mathrm{CI} 95 \%=10.9-17.6)$ and $7 \mathrm{mmHg}(\mathrm{CI} 95 \%=5.2-$ 9.1), respectively. Regarding this matter, Krane et al. report a mean pressure gradient of $8.9+-3.8 \mathrm{mmHg}$ at discharge, which remained stable within the first postoperative year, Ozaki et al. report a mean peak gradient of $15.2+-6.3 \mathrm{mmHg}$ on average 8 years after surgery. Similar results have been observed in other series. ${ }^{10,18,21-23}$

This excellent hemodynamic performance is the result of preserving the natural motion of the aortic valve annulus and the coordination of the left ventricle, aortic annulus, sinus of Valsalva, and aorta. This is particularly important in patients with a small AV annulus. ${ }^{10,18,26}$

\section{Freedom from reoperation and aortic insufficiency [?]II}

This is the main point of discussion, the AVRec surgery must still demonstrate long-term durability and to have accurate evidence we need comparative studies mainly with mechanical prostheses.

Benedetto et al. realized a meta-analytic comparison between series on AVRec surgery and biological prosthesis (Trifecta, Magna Ease, Freedom Solo, Freestyle, Mitroflow and autograft aortic valve). Meta-analytic estimates showed non-significant difference between AV reconstruction surgery and all but Magna Ease valves 
with regards to structural valve degeneration, re-intervention and endocarditis. When compared Magna Ease valve, $\mathrm{AV}$ reconstruction and other valve substitutes showed an excess of valve-related events. ${ }^{27}$

In the follow-up, we have not reoperated any patient for valve dysfunction. Survival free of AV insufficiency> II is $91.7 \%$ (Figure $2 \mathrm{C}$ ).

Ozaki et al. report freedom from death, cumulative incidence of reoperation, and that of recurrent moderate aortic regurgitation or greater was $85.9 \%, 4.2 \%$, and $7.3 \%$, respectively, after a mean follow-up period of 53.7 +- 28.2 months. Reoperations were performed in 15 patients $(0.4 \%$ per patient-year $)$, in 13 of which the reoperation was due to infective endocarditis. Krane et al. report on 4 patients undergoing reoperation; 2 because of early valve insufficiency, one due to endocarditis 6 weeks postoperatively, and 1 patient due to aortic valve insufficiency 2 years after surgery. Freedom from aortic insufficiency [?] grade II at 12 and 24 months was $98.2 \%+-0.02 \%$ and $92.1 \%+-0.05 \%$, respectively. Other surgeons report similar results. ${ }^{(18,20-22,27)}$

\section{Oral anticoagulant therapy}

Ten of the thirty-eight (26\%) patients in our series received AOC therapy, they have a mechanical MV or chronic AF. The rest of the patients received low doses of aspirin for at least 6 months. None of the patients who underwent AVRec surgery as a single procedure (42\%) received AOC therapy. We believe that this is one of the main advantages of this procedure, which is essential in developing countries, as we mentioned previously.

\section{Study limitations}

This is a retrospective study showing the medium-term results from a short series of a single hospital. We need analytical studies that compare AVRec surgery with valve replacement to have quality scientific evidence.

\section{CONCLUSION}

Mid-term outcome follow-up of AVRec surgery showed optimal results in term of mortality, reoperation free survival and hemodynamic characteristics of the neo-AV. We need more evidence derived from long-term or analytical studies, however the initial results are very promising.

\section{REFERENCES}

1. Iung B, Delgado V, Rosenhek R, Price S, Prendergast B, Wendler O, et al., EORP VHD II Investigators. Contemporary presentation and management of valvular heart disease: The EURObservational Research Programme Valvular Heart Disease II Survey. Circulation 2019; 140:1156-1169.

2. Yadgir S, Johnson CO, Aboyans V, Adebayo OM, Adedoyin RA, Afarideh M, et al., Global Burden of Disease Study Nonrheumatic Valve Disease Collaborators. Global, regional, and national burden of calcific aortic valve and degenerative mitral valve diseases, 1990-2017. Circulation 2020; 141:1670-1680.

3. Biteker N, Altum I, Basaran O et al. Treatment of Prosthectic Valve Thrombosis: Current Evidence and Future Directions. J Clin Med Res. 2015 Dec; 7 (12): 932-936.

4. Ozaki S. Pathophysiology of calcification of bioprosthetic heart valve: an experimental investigation. Acta Biomedica Lovaniensia. Vol 238. Leuven University Press; 2001.

5. Pibarot P, Dumesnil JG. Prosthesis-patient mismatch: definition, clinical impact and prevention. Heart.2006 Aug;92(8):1022-1029.

6. Lansac E, Di Centa I, Raoux F, Al Attar N, Acar C, Joudinaud T, et al. A lesional classification to standardize surgical management of aortic insufficiency towards valve repair. Eur J Cardiothorac Sur. 2008; 33:872-80.

7. Doss M, Sirat S, Risteski P, Martens S, Moritz A. Pericardial patch augmentation for repair of incompetent bicuspid aortic valves at midterm. Eur J Cardiothorac Surg. 2008 May;33(5):881-4.

8. Boodhwani M, El Khoury G. Aortic Valve Repair. Operative Techniques in Thoracic and Cardiovascular Surgery. Winter 2009 Volume 14, Issue 4, Pages 266-280. 
9. Duran CMG, Gometza B, Kumar N, Gallo R, Martin-Duran R. Aortic valve replacement with freehand autologous pericardium. J Thorac Cardiovasc Surg. 1995; 110:511-6.

10. Ozaki S, Kawase I, Yamashita H, Uchida S, Nozawa Y, Takatoh M, Hagiwara S. A total of 404 cases of aortic valve reconstruction with glutaraldehydetreated autologous pericardium. J Thorac Cardiovasc Surg. 2014 Jan;147(1):301-6.

11. Sa MPBO, Perazzo AM, Zhigalov K, Komarov R, Kadyraliev B, Enginoev S, Ennker J, Popov AF, Quarto C, Weymann A, Lima RC. Aortic Valve Neocuspidization with Glutaraldehyde-Treated Autologous Pericardium (Ozaki Procedure) - A Promising Surgical Technique. Braz J Cardiovasc Surg. 2019 Dec 1;34(5):610-614.

12. Yepez C, Rios J. Pulmonary valve reconstruction using Ozaki's technique for infective endocarditis. Eur J Cardiothorac Surg. 2021 Apr 29;59(4):917-919.

13. Rios J, Davila-Durand M, Aranda-Pretell N, Robles-Velarde V, Perez Valverde Y. Reconstruccion de la valvula pulmonar. Una alternativa quirurgica a considerar? Arch Peru Cardiol Cir Cardiovasc [Internet]. 1 de marzo de 2021 [citado 4 de diciembre de 2021];2(1):72-3.

14. Ozaki S, Kawase I, Yamashita H, Uchida S, Nozawa Y, Matsuyama T, et al. Aortic valve reconstruction using self-developed aortic valve plasty system in aortic valve disease. Interact Cardiovasc Thorac Surg. 2011; 12:550-3.

15. Bevan GH, Zidar DA, Josephson RA, Al-Kindi SG. Mortality Due to Aortic Stenosis in the United States, 2008-2017. JAMA. 2019;321(22):2236-2238.

16. Vahanian A, Beyersdorf F, Praz F, Milojevic M, Baldus S, Bauersachs J, et al., ESC/EACTS Scientific Document Group, 2021 ESC/EACTS Guidelines for the management of valvular heart disease: Developed by the Task Force for the management of valvular heart disease of the European Society of Cardiology (ESC) and the European Association for Cardio-Thoracic Surgery (EACTS), European Heart Journal, 2021; , ehab395.

17. Frankl WS. The special problems of the patient with a valvular prosthesis. Cardiovascular Clinics. $1986 ; 16(2): 415-426$.

18. Pirola S, Mastroiacovo G, Arlati F, Mostardini G, Bonomi A, Penza E, Polvani G, Single center 5-years' experience of Ozaki procedure: mid-term follow-up, The Annals of Thoracic Surgery (2020),

19. Zilla P, Brink J, Human P, Bezuidenhout D. Prosthetic heart valves: Catering for the few. Biomaterials Volume 29, Issue 4, February 2008, Pages 385-406.

20. Ozaki S, Kawase I, Yamashita H, Uchida S, Takatoh M, Kiyohara N. Midterm outcomes after aortic valve neocuspidization with glutaraldehyde-treated autologous pericardium. J Thorac Cardiovasc Surg. 2018;155(6):2379-87.

21. Krane M, Boehm J, Prinzing A, Ziegelmueller J, Holfeld J, Lange R. Excellent Hemodynamic Performance After Aortic Valve Neocuspidization Using Autologous Pericardium. Ann Thorac Surg. 2020.

22. Iida Y, Fujii S, Akiyama S, Sawa S. Early and mid-term results of isolated aortic valve neocuspidization in patients with aortic stenosis. Gen Thorac Cardiovasc Surg 2018;66:648-52.

23. Ngo HT, Nguyen HC, Nguyen TT, Le TN, Camilleri L, Doan HQ. Reconstruction of aortic valve by autologous pericardium (Ozaki's procedure): Single center experience in Vietnam. Asian Cardiovasc Thorac Ann. 2021 Jun;29(5):394-399.

24. Iida Y, Sawa S, Fujii S, Shimizu H. Aortic valve neocuspidization in patients under 65 years old. Gen Thorac Cardiovasc Surg. 2020;68(8):780-4.

25. Ozaki S, Kawase I, Yamashita H, Nozawa Y, Takatoh M, Hagiwara S, Kiyohara N. Aortic valve reconstruction using autologous pericardium for patients aged less than 60 years. J Thorac Cardiovasc Surg. 2014 Sep;148(3):934-8.

26. Iida Y, Akiyama S, Shimura K, Fujii S, Hashimoto C, Mizuuchi S, et al. Comparison of aortic annulus dimensions after aortic valve neocuspidization with those of normal aortic valve using transthoracic echocardiography. Eur J Cardio-Thoracic Surg. 2018;54(6): 1081-4.

27. Benedetto U, Sinha S, Dimagli A, Dixon L, Stoica S, Cocomello L, Quarto C, Angelini GD, Dandekar U, Caputo M. Aortic valve neocuspidization with autologous pericardium in adult patients: UK experience and meta-analytic comparison with other aortic valve substitutes. Eur J Cardiothorac Surg. 2021 Jul 
14;60(1):34-46.

\begin{tabular}{|c|c|c|}
\hline $\begin{array}{l}\text { Table 1: Baseline } \\
\text { characteristics of } \\
\text { patients }(n=38)\end{array}$ & $\begin{array}{l}\text { Table 1: Baseline } \\
\text { characteristics of } \\
\text { patients }(n=38)\end{array}$ & $\mathrm{n}(\%)$ \\
\hline Age (years) & $62[25] *$ & $62[25] *$ \\
\hline \multicolumn{3}{|l|}{ Sex } \\
\hline Male & $19(50)$ & $19(50)$ \\
\hline Female & $19(50)$ & $19(50)$ \\
\hline BMI $\left(\mathrm{kg} / \mathrm{m}^{2}\right)$ & $25.5[4] \#$ & $25.5[4] \#$ \\
\hline Underweight $(<19)$ & $1(2.6)$ & $1(2.6)$ \\
\hline Normal $(19-24.99)$ & $17(44.7)$ & $17(44.7)$ \\
\hline Overweight $(25-29.99)$ & $15(39.5)$ & $15(39.5)$ \\
\hline Obesity ([?]30) & $5(13.2)$ & $5(13.2)$ \\
\hline \multicolumn{3}{|l|}{ Functional Class (NYHA) } \\
\hline I & $1(2.6)$ & $1(2.6)$ \\
\hline II & $19(50)$ & $19(50)$ \\
\hline III & $18(47.4)$ & $18(47.4)$ \\
\hline \multicolumn{3}{|l|}{ AV disease } \\
\hline Stenosis & $24(63.1)$ & $24(63.1)$ \\
\hline Insufficiency & $12(31.6)$ & $12(31.6)$ \\
\hline Prosthesis dysfunction & $2(5.3)$ & $2(5.3)$ \\
\hline \multicolumn{3}{|l|}{ AV morphology } \\
\hline Unicuspid & $1(2.6)$ & $1(2.6)$ \\
\hline Bicuspid & $19(50)$ & $19(50)$ \\
\hline Tricuspid & $16(42.1)$ & $16(42.1)$ \\
\hline Prosthesis & $2(5.3)$ & $2(5.3)$ \\
\hline AV annulus (mm) & $23[5] *$ & $23[5]^{*}$ \\
\hline [?]21 & $13(34.2)$ & $13(34.2)$ \\
\hline Peak AV gradient (mmHg) & $73[78] *$ & $73[78] *$ \\
\hline Mean AV gradient (mmHg) & $46[48] *$ & $46[48] *$ \\
\hline LVEF (\%) & $59[16] *$ & $59[16] *$ \\
\hline $\mathrm{LVEF}<40 \%$ & $5(13.2)$ & $5(13.2)$ \\
\hline \multicolumn{3}{|l|}{ Concomitant pathology } \\
\hline Ascending aorta aneurysm & $8(21)$ & $8(21)$ \\
\hline TV insufficiency & $8(21)$ & $8(21)$ \\
\hline MV disease & $8(21)$ & $8(21)$ \\
\hline Coronary artery disease & $6(15.8)$ & $6(15.8)$ \\
\hline \multicolumn{3}{|l|}{ Other basal characteristics } \\
\hline Hypertension & $15(39.5)$ & $15(39.5)$ \\
\hline Diabetes & $8(21.1)$ & $8(21.1)$ \\
\hline Chronic atrial fibrillation & $8(21.1)$ & $8(21.1)$ \\
\hline Euroscore II (\%) & $1.6[1.9]^{*}$ & $1.6[1.9]^{*}$ \\
\hline $\mathrm{ES}$ II $>5 \%$ & $5(13.2)$ & $5(13.2)$ \\
\hline
\end{tabular}




\begin{tabular}{|c|c|c|}
\hline $\begin{array}{l}\text { Table 1: Baseline } \\
\text { characteristics of } \\
\text { patients }(n=38)\end{array}$ & $\begin{array}{l}\text { Table 1: Baseline } \\
\text { characteristics of } \\
\text { patients }(n=38)\end{array}$ & n $(\%)$ \\
\hline $\begin{array}{l}\mathrm{BMI}=\text { body mass index, } \\
\mathrm{Kg}=\text { kilogram, m=meter, } \\
\mathrm{NYHA}=\text { new year heart } \\
\text { association } \mathrm{AV}=\text { aortic valve, } \\
\mathrm{LVEF}=\text { left ventricular ejection } \\
\text { fraction, TV=tricuspid valve, } \\
\mathrm{MV}=\text { mitral valve, } \\
\mathrm{ES}=\text { Euroscore, }{ }^{*} \text { Values } \\
\text { expressed as median and } \\
\text { interquartile range, \#Values } \\
\text { expressed as mean and standard } \\
\text { deviation. }\end{array}$ & $\begin{array}{l}\mathrm{BMI}=\text { body mass index, } \\
\mathrm{Kg}=\text { kilogram, } \mathrm{m}=\text { meter, } \\
\mathrm{NYHA}=\text { new year heart } \\
\text { association } \mathrm{AV}=\text { aortic valve, } \\
\mathrm{LVEF}=\text { left ventricular ejection } \\
\text { fraction, } \mathrm{TV}=\text { tricuspid valve, } \\
\mathrm{MV}=\text { mitral valve, } \\
\mathrm{ES}=\text { Euroscore, }{ }^{*} \text { Values } \\
\text { expressed as median and } \\
\text { interquartile range, }{ }^{\#} \text { Values } \\
\text { expressed as mean and standard } \\
\text { deviation. }\end{array}$ & $\begin{array}{l}\mathrm{BMI}=\text { body mass index, } \\
\mathrm{Kg}=\text { kilogram, m=meter, } \\
\mathrm{NYHA}=\text { new year heart } \\
\text { association } \mathrm{AV}=\text { aortic valve, } \\
\mathrm{LVEF}=\text { left ventricular ejection } \\
\text { fraction, } \mathrm{TV}=\text { tricuspid valve, } \\
\mathrm{MV}=\text { mitral valve, } \\
\mathrm{ES}=\text { Euroscore, }{ }^{*} \text { Values } \\
\text { expressed as median and } \\
\text { interquartile range, }{ }^{\text {Values }} \\
\text { expressed as mean and standard } \\
\text { deviation. }\end{array}$ \\
\hline
\end{tabular}

Table 2A: Surgical procedures characteristics $(\mathrm{n}=38)$ n $(\%)$

\begin{tabular}{ll}
\hline CPB time (minutes) & $147[46]^{*}$ \\
Cross clamp time (minutes) & $120[45]^{*}$ \\
AV reconstruction single procedure & $16(42)$ \\
AV reconstruction + other procedure & $22(58)$ \\
MV surgery & $8(21)$ \\
AA surgery & $8(21)$ \\
TV repair & $9(23.7)$ \\
CABG & $8(21)$ \\
Surgical approach & $35(92.1)$ \\
Full sternotomy & $3(7.9)$ \\
"J" Mini-sternotomy & Table 2B: Early post-operative evolution \\
Table 2B: Early post-operative evolution & $($ first 30 days) n (\%) \\
(first 30 days) n (\%) & $3[2]^{*}$ \\
ICU stay & $10[4] *$ \\
In hospital stay & \\
Perioperative complications & $0(0)$ \\
Stroke & $1(2.6)$ \\
Definitive Pacemaker & $2(5.2)$ \\
Redo-surgery for excessive bleeding & $1(2.6)$ \\
Tracheostomy & $2(5.2)$ \\
Perioperative myocardial infarction & $1(2.6)$ \\
Mortality & CPB= Cardiopulmonary bypass, AV=Aortic \\
CPB= Cardiopulmonary bypass, AV=Aortic & valve, MV=Mitral valve, AA=Ascending aorta, \\
valve, MV=Mitral valve, AA=Ascending aorta, & TV=Tricuspid valve, CABG: Coronary artery \\
TV=Tricuspid valve, CABG: Coronary artery & bypass grafting, ICU: Intensive care unit, *Values \\
bypass grafting, ICU: Intensive care unit, *Values & expressed as median and interquartile range. \\
expressed as median and interquartile range. & \\
\hline
\end{tabular}




\begin{tabular}{|c|c|c|c|c|c|c|c|}
\hline \multirow[t]{2}{*}{$\begin{array}{l}\text { Table } 3 . \\
\text { Out- } \\
\text { comes in } \\
\text { baseline, } \\
\text { perioper- } \\
\text { ative } \\
\text { period } \\
\text { and } \\
\text { extended } \\
\text { follow-up } \\
(n=38)\end{array}$} & $\begin{array}{l}\text { Table } 3 . \\
\text { Out- } \\
\text { comes in } \\
\text { baseline, } \\
\text { perioper- } \\
\text { ative } \\
\text { period } \\
\text { and } \\
\text { extended } \\
\text { follow-up } \\
(n=38)\end{array}$ & $\begin{array}{l}\text { Table } 3 . \\
\text { Out- } \\
\text { comes in } \\
\text { baseline, } \\
\text { perioper- } \\
\text { ative } \\
\text { period } \\
\text { and } \\
\text { extended } \\
\text { follow-up } \\
(n=38)\end{array}$ & $\begin{array}{l}\text { Table } 3 . \\
\text { Out- } \\
\text { comes in } \\
\text { baseline, } \\
\text { perioper- } \\
\text { ative } \\
\text { period } \\
\text { and } \\
\text { extended } \\
\text { follow-up } \\
(n=38)\end{array}$ & $\begin{array}{l}\text { Table } 3 . \\
\text { Out- } \\
\text { comes in } \\
\text { baseline, } \\
\text { perioper- } \\
\text { ative } \\
\text { period } \\
\text { and } \\
\text { extended } \\
\text { follow-up } \\
(n=38)\end{array}$ & $\begin{array}{l}\text { Table } 3 . \\
\text { Out- } \\
\text { comes in } \\
\text { baseline, } \\
\text { perioper- } \\
\text { ative } \\
\text { period } \\
\text { and } \\
\text { extended } \\
\text { follow-up } \\
\text { (n=38) }\end{array}$ & & \\
\hline & Baseline & $\begin{array}{l}\text { Periopera } \\
\text { period * }\end{array}$ & $\begin{array}{l}\text { Extended } \\
\text { follow } \\
\text { up }^{\#}\end{array}$ & & & & \\
\hline \multicolumn{5}{|c|}{$\begin{array}{l}\text { Echocardiograpledian(CI95\%)edian(CI95\%)edian(CI95\%) value }{ }^{\text {a }} \\
\text { parame- } \\
\text { ters }\end{array}$} & p-value ${ }^{b}$ & $p_{\text {-value }}{ }^{b}$ & p-value ${ }^{b}$ \\
\hline $\begin{array}{l}\text { AV peak } \\
\text { gradient }\end{array}$ & $\begin{array}{l}66 \\
(52.5-81.3)\end{array}$ & $\begin{array}{l}15 \\
(12.1-17.5)\end{array}$ & $\begin{array}{l}14 \\
(10.9-17.6)\end{array}$ & $<0.0001$ & $<0.0001$ & $<0.0001$ & $<0.0001$ \\
\hline $\begin{array}{l}\text { AV mean } \\
\text { gradient }\end{array}$ & $\begin{array}{l}41 \\
31.8-50.1)\end{array}$ & $8(6.0-9.6)$ & $7(5.2-9.1)$ & $<0.0001$ & $<0.0001$ & $<0.0001$ & $<0.0001$ \\
\hline $\operatorname{LVEF}(\%)$ & $\begin{array}{l}57 \\
(52.8-61.5)\end{array}$ & $\begin{array}{l}58 \\
(53.6-60.8)\end{array}$ & $\begin{array}{l}59(56.1- \\
61.7)\end{array}$ & 0.8127 & 0.1928 & 0.1928 & 0.1928 \\
\hline $\begin{array}{l}\text { Aortic } \\
\text { insuffi- } \\
\text { ciency }\end{array}$ & $\mathbf{n}(\%)$ & $\mathbf{n}(\%)$ & $\mathbf{n}(\%)$ & $p_{\text {-value }}{ }^{c}$ & $p_{\text {-value }}{ }^{d}$ & $p_{\text {-value }}{ }^{d}$ & $p_{\text {-value }}{ }^{d}$ \\
\hline 0 & 7 & $22(61)$ & $21(58)$ & $0.0018^{\mathrm{e}}$ & $0.0213^{\mathrm{e}}$ & $0.0213^{\mathrm{e}}$ & $0.0213^{\mathrm{e}}$ \\
\hline I & 6 & $13(36)$ & $12(33)$ & & & & \\
\hline II & 9 & $1(3)$ & $2(6)$ & & & & \\
\hline III & 4 & $0(0)$ & $1(3)$ & & & & \\
\hline IV & 12 & $0(0)$ & $0(0)$ & & & & \\
\hline $\begin{array}{l}\text { Clinical } \\
\text { variables }\end{array}$ & $\mathbf{n}(\%)$ & $\mathbf{n}(\%)$ & $\mathbf{n}(\%)$ & & & & \\
\hline $\begin{array}{l}\text { All-cause } \\
\text { mortality }\end{array}$ & - & $1(2.6)$ & $2(5.3)$ & & & & \\
\hline Stroke & - & $0(0)$ & $0(0)$ & & & & \\
\hline $\begin{array}{l}\text { Myocardial } \\
\text { infarction }\end{array}$ & - & $2(5.3)$ & $2(5.3)$ & & & & \\
\hline ACO use & $8(21)$ & $8(21)$ & $10(26)$ & & & & \\
\hline $\begin{array}{l}\text { Definitive } \\
\text { pacemaker }\end{array}$ & - & $1(2.6)$ & $2(5.3)$ & & & & \\
\hline $\begin{array}{l}\text { Redo- } \\
\text { surgery for } \\
\text { valve } \\
\text { dysfunction }\end{array}$ & - & $0(0)$ & $0(0)$ & & & & \\
\hline $\begin{array}{l}\text { Functional } \\
\text { Class } \\
(\text { NYHA) }\end{array}$ & $\mathbf{n}(\%)$ & $\mathbf{n}(\%)$ & $\mathbf{n}(\%)$ & & & & \\
\hline I & $1(2.6)$ & $15(41)$ & $32(84)$ & & & & \\
\hline II-III & 37 (97.4) & $21(53)$ & $4(11)$ & & & & \\
\hline
\end{tabular}




\begin{tabular}{|c|c|c|c|c|c|c|}
\hline $\begin{array}{l}\text { Table } 3 . \\
\text { Out- } \\
\text { comes in } \\
\text { baseline, } \\
\text { perioper- } \\
\text { ative } \\
\text { period } \\
\text { and } \\
\text { extended } \\
\text { follow-up } \\
(\mathrm{n}=38)\end{array}$ & $\begin{array}{l}\text { Table } 3 . \\
\text { Out- } \\
\text { comes in } \\
\text { baseline, } \\
\text { perioper- } \\
\text { ative } \\
\text { period } \\
\text { and } \\
\text { extended } \\
\text { follow-up } \\
(n=38)\end{array}$ & $\begin{array}{l}\text { Table } 3 . \\
\text { Out- } \\
\text { comes in } \\
\text { baseline, } \\
\text { perioper- } \\
\text { ative } \\
\text { period } \\
\text { and } \\
\text { extended } \\
\text { follow-up } \\
(n=38)\end{array}$ & $\begin{array}{l}\text { Table } 3 . \\
\text { Out- } \\
\text { comes in } \\
\text { baseline, } \\
\text { perioper- } \\
\text { ative } \\
\text { period } \\
\text { and } \\
\text { extended } \\
\text { follow-up } \\
(n=38)\end{array}$ & $\begin{array}{l}\text { Table } 3 . \\
\text { Out- } \\
\text { comes in } \\
\text { baseline, } \\
\text { perioper- } \\
\text { ative } \\
\text { period } \\
\text { and } \\
\text { extended } \\
\text { follow-up } \\
(n=38)\end{array}$ & $\begin{array}{l}\text { Table } 3 . \\
\text { Out- } \\
\text { comes in } \\
\text { baseline, } \\
\text { perioper- } \\
\text { ative } \\
\text { period } \\
\text { and } \\
\text { extended } \\
\text { follow-up } \\
(n=38)\end{array}$ & \\
\hline * first 30 & * first 30 & $*$ first 30 & $*$ first 30 & $*$ first 30 & * first 30 & * first 30 \\
\hline $\begin{array}{l}\text { postopera- } \\
\text { tive days, } \\
\# 19\end{array}$ & $\begin{array}{l}\text { postopera- } \\
\text { tive days, } \\
\text { \# } 19\end{array}$ & $\begin{array}{l}\text { postopera- } \\
\text { tive days, } \\
\text { \# } 19\end{array}$ & $\begin{array}{l}\text { postopera- } \\
\text { tive days, } \\
\text { \# } 19\end{array}$ & $\begin{array}{l}\text { postopera- } \\
\text { tive days, } \\
\text { \# } 19\end{array}$ & $\begin{array}{l}\text { postopera- } \\
\text { tive days, } \\
\text { \# } 19\end{array}$ & $\begin{array}{l}\text { postopera- } \\
\text { tive days, } \\
\text { \# } 19\end{array}$ \\
\hline months on & months on & months on & months on & months on & months on & months on \\
\hline average a & average a & average a & average a & average a & average a & average a \\
\hline Wilcoxon & Wilcoxon & Wilcoxon & Wilcoxon & Wilcoxon & Wilcoxon & Wilcoxon \\
\hline signed- & signed- & signed- & signed- & signed- & signed- & signed- \\
\hline rank test & rank test & rank test & rank test & rank test & rank test & rank test \\
\hline & for & for & for & for & for & for \\
\hline dependent & dependent & dependent & dependent & dependent & dependent & dependent \\
\hline measures & measures & measures & measures & measures & measures & measures \\
\hline $\begin{array}{l}\text { (perioper- } \\
\text { ative }\end{array}$ & $\begin{array}{l}\text { (perioper- } \\
\text { ative }\end{array}$ & $\begin{array}{l}\text { (perioper- } \\
\text { ative }\end{array}$ & $\begin{array}{l}\text { (perioper- } \\
\text { ative }\end{array}$ & $\begin{array}{l}\text { (perioper- } \\
\text { ative }\end{array}$ & $\begin{array}{l}\text { (perioper- } \\
\text { ative }\end{array}$ & $\begin{array}{l}\text { (perioper- } \\
\text { ative }\end{array}$ \\
\hline period vs & period vs & period vs & period vs & period vs & period vs & period vs \\
\hline baseline) b & baseline) b & baseline) b & baseline) b & baseline) b & baseline) b & baseline) b \\
\hline Wilcoxon & Wilcoxon & Wilcoxon & Wilcoxon & Wilcoxon & Wilcoxon & Wilcoxon \\
\hline signed- & signed- & signed- & signed- & signed- & signed- & signed- \\
\hline rank test & rank test & rank test & rank test & rank test & rank test & rank test \\
\hline & & for & for & for & for & for \\
\hline dependent & dependent & dependent & dependent & dependent & dependent & dependent \\
\hline measures & measures & measures & measures & measures & measures & measures \\
\hline (extended & (extended & (extended & (extended & (extended & (extended & (extended \\
\hline follow-up & follow-up & follow-up & follow-up & follow-up & follow-up & follow-up \\
\hline vs & vs & vs & vs & vs & vs & vs \\
\hline baseline) c & baseline) c & baseline) c & baseline) c & baseline) c & baseline) c & baseline) c \\
\hline Exact & Exact & Exact & Exact & Exact & Exact & Exact \\
\hline McNemar & McNemar & McNemar & McNemar & McNemar & McNemar & McNemar \\
\hline test for & test for & test for & test for & test for & test for & test for \\
\hline dependent & dependent & dependent & dependent & dependent & dependent & dependent \\
\hline categorical & categorical & categorical & categorical & categorical & categorical & categorical \\
\hline measures & measures & measures & measures & measures & measures & measures \\
\hline $\begin{array}{l}\text { (perioper- } \\
\text { ative }\end{array}$ & $\begin{array}{l}\text { (perioper- } \\
\text { ative }\end{array}$ & $\begin{array}{l}\text { (perioper- } \\
\text { ative }\end{array}$ & $\begin{array}{l}\text { (perioper- } \\
\text { ative }\end{array}$ & $\begin{array}{l}\text { (perioper- } \\
\text { ative }\end{array}$ & $\begin{array}{l}\text { (perioper- } \\
\text { ative }\end{array}$ & $\begin{array}{l}\text { (perioper- } \\
\text { ative }\end{array}$ \\
\hline period up & period up & period up & period up & period up & period up & period up \\
\hline vs & vs & vs & vs & vs & vs & vs \\
\hline baseline) d & baseline) d & baseline) $\mathrm{d}$ & baseline) $\mathrm{d}$ & baseline) $\mathrm{d}$ & baseline) d & baseline) d \\
\hline Exact & Exact & Exact & Exact & Exact & Exact & Exact \\
\hline McNemar & McNemar & McNemar & McNemar & McNemar & McNemar & McNemar \\
\hline $\begin{array}{l}\text { test for } \\
\text { dependent }\end{array}$ & test for & test for & test for & test for & test for & test for \\
\hline $\begin{array}{l}\text { dependent } \\
\text { categorical }\end{array}$ & $\begin{array}{l}\text { dependent } \\
\text { categorical }\end{array}$ & $\begin{array}{l}\text { dependent } \\
\text { categorical }\end{array}$ & $\begin{array}{l}\text { dependent } \\
\text { categorical }\end{array}$ & $\begin{array}{l}\text { dependent } \\
\text { categorical }\end{array}$ & $\begin{array}{l}\text { dependent } \\
\text { categorical }\end{array}$ & $\begin{array}{l}\text { dependent } \\
\text { categorical }\end{array}$ \\
\hline measures & measures & measures & measures & measures & measures & measures \\
\hline (extended & (extended & (extended & (extended & (extended & (extended & (extended \\
\hline follow-up & follow-up & follow-up & follow-up & follow-up & follow-up & follow-up \\
\hline vs & vs & vs & vs & vs & vs & vs \\
\hline baseline) e & baseline) e & baseline) e & baseline) e & baseline) e & baseline) e & baseline) e \\
\hline Hypothe- & Hypothe- & Hypothe- & Hypothe- & Hypothe- & Hypothe- & Hypothe- \\
\hline
\end{tabular}




\begin{tabular}{llllll}
\hline Table 3. & Table 3. & Table 3. & Table 3. & Table 3. & Table 3. \\
Out- & Out- & Out- & Out- & $\begin{array}{l}\text { Out- } \\
\text { comes in }\end{array}$ & $\begin{array}{l}\text { comes in } \\
\text { comes in }\end{array}$ \\
comes in & comes in & comes in & comel \\
baseline, & baseline, & baseline, & baseline, & baseline, & baseline, \\
perioper- & perioper- & perioper- & perioper- & perioper- & perioper- \\
ative & ative & ative & ative & ative & ative \\
period & period & period & period & period & period \\
and & and & and & and & and & and \\
extended & extended & extended & extended & extended & extended \\
follow-up & follow-up & follow-up & follow-up & follow-up & follow-up \\
$(\mathrm{n}=38)$ & $(\mathrm{n}=38)$ & $(\mathrm{n}=38)$ & $(\mathrm{n}=38)$ & $(\mathrm{n}=38)$ & $(\mathrm{n}=38)$ \\
\hline
\end{tabular}

\section{FIGURE LEGENDS}

Figure 1: Two neo-AV after reconstruction of the three leaflets.

Figure 2 A, B: Kaplan Meier method showing survival data. C: Graph box showing the evolution of the AV gradients t1: baseline characteristics, t2: early postoperative evolution, t3: follow up

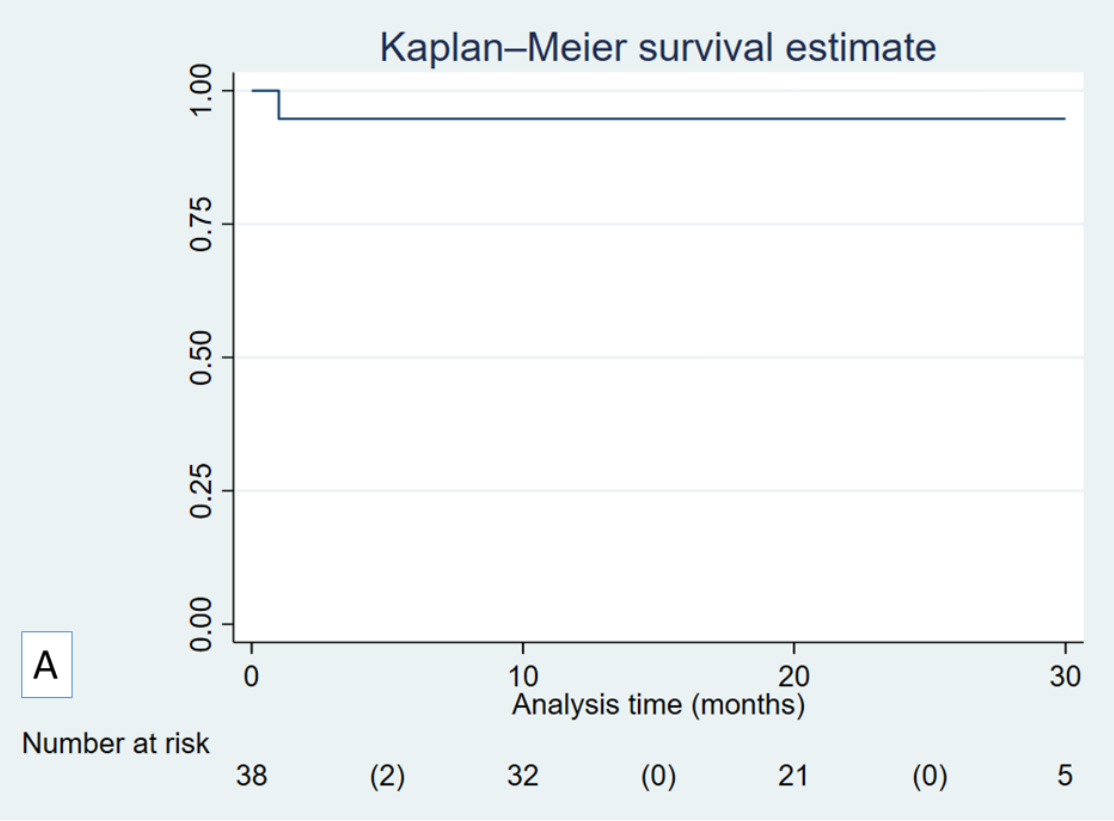



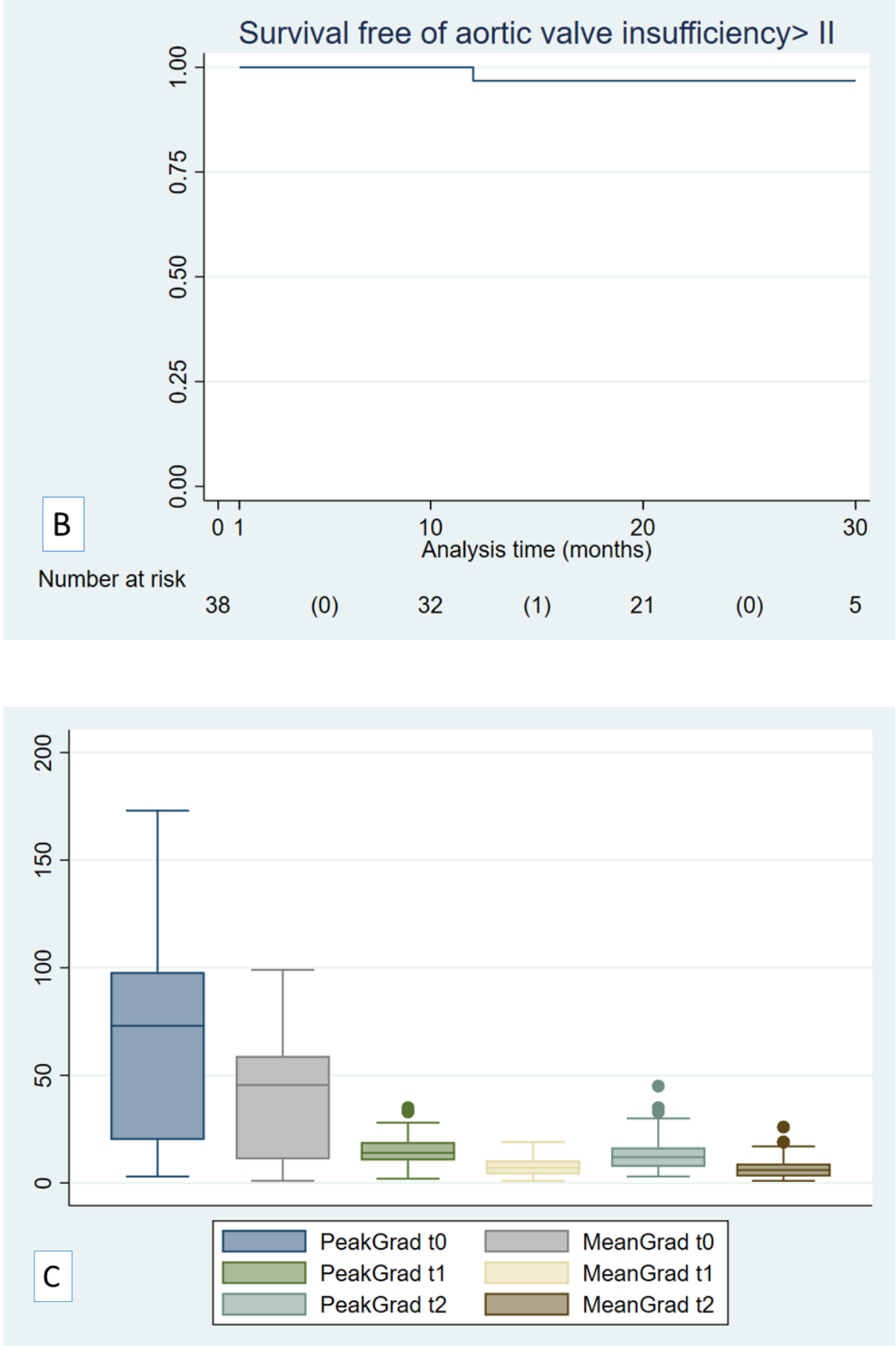